\title{
Factors influencing psychoactive substance use among adolescents in public secondary schools in Uganda
}

\author{
Aloysius Rukundo ${ }^{1}$, Grace Kibanja ${ }^{2}$, and Karl Steffens ${ }^{3}$ \\ ${ }^{1}$ Department of Educational Foundations and Psychology, Mbarara University of Science and Technology, Mbarara, Uganda \\ ${ }^{2}$ Department of Psychology, Makerere University, Kampala, Uganda \\ ${ }^{3}$ University of Cologne, Cologne, Germany
}

\begin{abstract}
Introduction: Studies exploring psychoactive substance use (PASU) among adolescents report a variety of both intrapersonal and interpersonal negatively and positively reinforcing factors. While existing studies have looked at factors affecting PASU among adolescents in general, little has been done to explore such factors in schools.

Objective: This paper examines the factors that influence PASU among adolescents in Ugandan public schools.

Methods: The study generated data from 12 focus group discussions (FGDs), based on a qualitative, cross-sectional exploratory design using purposive sampling. We used a focus group guide based on the question: What factors influence use of psychoactive substances among students in your school?

Results: All focus groups noted peer pressure as the strongest factor influencing use of substances in schools, with relief from domestic stress being identified as the second strongest factor. The FGDs tackled other factors related to PASU in public schools in Uganda, though not to as big of an extent.
\end{abstract}

Conclusion: Present study results generally seem to suggest that PASU among adolescents in public schools is a result of the interaction between adolescents, the substances in question, and the environment in which those adolescents live.

\section{Background}

Psychoactive substance use (PASU) among adolescents is an increasing subject of social and public health concern in most parts of the world (Conway et al., 2013; Thompson, Rivara, \& Whitehill, 2015; Yusoff et al., 2014). Previous and recent decades have seen both scientific sources and popular press in developed and developing countries devoting priority to PASU among youth (Botvin \& Griffin, 2007; Cronk \& Sarvela, 1997). Studies exploring PASU among adolescents consistently report on a variety of both intrapersonal and interpersonal negatively and positively reinforcing factors of substance use (Barnes, Welte, Tidwell, \& Hoffman, 2013; Dolcini et al., 2013; Pengpid \& Peltzer, 2013; Reddy, Resnicow, Omardien, \& Kambaran, 2007; Sanhueza, Delva, Bares, \& Grogan-Kaylor, 2013). It has been reported that prevalence and availability of psychoactive substances catalyzes their use among adolescents (Marks et al., 2005; Warren, Smalley, \& Barefoot, 2015).
Related earlier studies propose that adolescents with poor social attachment have weaker self-image and a greater need to portray themselves to their peers as "tough" or "cool" through experimenting with psychoactive substances (Marks et al., 2005; Perkins, 1997; Tulu \& Keskis, 2015). Broadly speaking, the concerns regarding factors responsible for the increasing use of psychoactive substances among adolescents undoubtedly cut across the social-care systems, including schools (e.g., Geramian, Akhavan, Gharaat, Tehrani, \& Farajzadegan, 2012; Moore \& Werch, 2005).

While most existing studies have explored the factors affecting PASU among adolescents in general, little has been done to explore about such factors in school contexts. And, to the best of our knowledge, no specific studies have been done regarding the factors affecting PASU among adolescents in public schools in Uganda. Moreover, miniature non-academic empirical sources are available to underpin the factors responsible for PASU in Ugandan schools. Yet schools are inclined to deal with the

Correspondence: Dr. Aloysius Rukundo, Mbarara University of Science and Technology, P.O. BOX 1410 MBARARA-Uganda, Email: arukundo@must.ac.ug; rukundoaloy@yahoo.com

Financial support: Financial support for this research was provided by the German Academic Exchange Services (DAAD) under grant code A/11/07117

Declaration of interest: The views and opinions expressed in this study are those of the authors and do not represent the views of DAAD. The authors report no conflict of interest and they alone are responsible for the content of the article.

Keywords: psychoactive substance use (PASU), school adolescents, factors, public schools, Uganda 
detrimental effects caused by PASU among youth (Kacwamu, 2010; Muggaga, 2010). The present study is timely in its tenacity of exploring the factors that influence PASU among students in public schools.

The context of the factors associated with PASU among students is well grounded in the diffusion and social learning theories of substance use (Donovan, 2004; Ferrence, 2001; Petraitis, Flay, \& Miller, 1995). The theory of diffusion is pertinent in expressing PASU as a "contagious" process and naturally spreading across school settings (Ferrence, 2001; Laflin, Edmundson, \& MooreHirschl, 1995). It is inferred here that PASU disperses from individual students to others and from one place to another. According to Ferrence (2001), the "contagion" mechanism of PASU follows a sideways spread whereby use of one substance leads to use of another. The diffusion theory for this reason underscores a possibility of new students acquiring PASU practices from cultures and subcultures of old students in schools. Substance use among adolescents seems to be systematically transmitted over existing friendship networks of drug users, and diffusion is believed to originate at a single point as it spreads outwards via media and person-to-person interactions (Ferrence, 2001).

In accordance with the social learning theory, PASU among students has been proven and regarded as a behavior that develops in response to the influence of significant other people (Colby et al, 2013; Giovazolias \& Themeli, 2014; Onya, Tessera, \& Myers, 2012). For instance, Donovan (2004) articulates that modeling of alcohol and drug use predicts initiation of its consumption among adolescents. That, perhaps, explains the stance by the social learning theorists in asserting that students' use of psychoactive substances relates to interaction with their school environments. It is asserted that interaction with peer groups encourages experimentation with psychoactive substances among school-going adolescents (McLeod, 2016). Similarly, PASU has previously been related to school neighborhood factors (Karriker-Jaffe et al., 2012; Milam, Furr-Holden, Harrell, Whitaker, \& Leaf, 2012; Oman, Tolma, Vesely, \& Aspy, 2013). Such a state of affairs catalyzes indulgence in substance use among adolescents and their peers, as previously opined by the social learning theorists.

Petraitis, Flay, and Miller (1995) succinctly elucidate a theoretical change away from the substance-specific beliefs of adolescents to possible causes of such beliefs. They maintain that sociologists and behaviorally oriented psychologists have built upon the social learning theory to assert that adolescents possibly acquire PASU behaviors from role models-especially peers and parents. For instance, it is widely documented that peer influence is a central factor in shaping adolescents' substance use and other interpersonal experiences (Rukundo, 2012; Walsh \& Tzelepis, 2007). Thus, behavioral/social learning theories of substance use focus on interactive or social engagements as conjoined elements predicting PASU among adolescents (Dokua, Koivusiltac, Raisamob, \& Rimpeläb, 2012; Fleary, Heffer, \& McKyer, 2013; Seay \& Kohl, 2013).
In the most specific terms, the theoretical argument regarding social learning alludes to adolescents' involvement with substance-using "role models" as being likely to have three sequential effects: (1) the observation and imitation of substance-specific behaviors; (2) social reinforcement; and (3) expectation of positive social and physiological outcomes from future PASU (Petraitis et al., 1995). The social learning theory moreover reaffirms adolescent socialization as reflected in imitation and reinforcement (Kandel \& Andrews, 1987). In essence, the social learning point of view assumes that adolescents become addicted to psychoactive substances through repeated association, reinforcement, and modeling (Caprara, Regalia, \& Bandura, 2002; Hockenbury \& Hockenbury, 2006; Karen, 1993).

Despite the theoretical artifacts vis-à-vis factors of PASU, substance use among students notably results in negative effects, contrary to adolescents' portraits of positive images of substance use (Agius, Taft, Hemphill, Toumbourou, \& McMorris, 2013). Positive imageries regarding PASU are exacerbated and glamorized by the media with a purpose of attracting and motivating students to use psychoactive substances (Kalichman, Simbayi, Kaufman, Cain, \& Jooste, 2007; Sznitman \& Romer, 2014). The media is therefore one of the aspects associated with PASU reinforcement among students (American Academy of Pediatrics, 2010). For instance, the American Academy of Pediatrics (2010) accordingly predicts that cigarette advertising increases teenagers' risk of smoking by glamorizing smoking and smokers. Smoking is subsequently depicted as being associated with modern life, having fun, and being stylish, without featuring its adverse consequences (Mpabulungi, 2003).

In addition to media exposure, it is well-known that family environment influences adolescents to take psychoactive substances (Brook, Pahl, Morojere, \& Brook, 2006). Stressful family situations and uncertainty due to family breakdown could lead to an increase in PASU behaviors among adolescents and children (Wood, 2009). Similarly, a positive correlation exists between levels of alcohol use and abuse and the amount of daily stress and conflict within a family (Donovan, 2004; Wood, 2009). In the same way, several examples of family stressors such as single parenthood and parental drug addiction seem to exacerbate PASU among adolescents (Brook, Pahl, Morojere, \& Brook, 2006; Wood, 2009).

The home initially and traditionally is considered the primary source where school-age children begin to draw their views of alcohol and its subsequent use (Conway et al., 2013; Wallace \& Muroff, 2002; Yusoff et al., 2014). Furthermore, it has been suggested that family attitudes towards PASU behavior, poor and inconsistent family management practices, high levels of family conflict, and low family bonding work in unison to enable substance use among adolescents (Wallace \& Muroff, 2002). The family's view on use of a particular substance therefore seems to play a large part in development of the child's perception toward PASU (Telzer, Gonzales, \& Fuligni, 2013). 
Extensive review of previous studies presumably provides a strong ground to discern that contextual and familial factors influencing substance use among students vary widely. The general consensus, however, seems to allude to inner and outer influences of substance use. It is nevertheless worth noting that substance use does not solve students' problems but only masks sensations and often makes problems worse. Investigating the factors associated with PASU among public schools in Uganda may well become a step forward in overcoming harmful consequences of substance use. The present study was consequently instituted to answer the question: what factors influence use of psychoactive substances among adolescents in public secondary schools in Uganda?

\section{Methods}

\section{Study Settings}

The study was conducted in four major geographical regions of Uganda, comprising the Western, Eastern, Northern, and Central regions. The regions of Uganda were unique in their socio-cultural settings, giving the students in the respective schools a diversified background. We therefore utilized students' diverse backgrounds to deduce a comprehensive representation of the study subject. The study selected public schools from urban areas around Uganda's capital city Kampala and ten municipalities. Choice of school was informed by the nature of the institution, which is to provide affordable education to urban children from low socio-economic status families. For this reason, these schools are congested with students, many of whom commute from far distances on a daily basis. The consistent interaction of students with regular urban communities is therefore an important consideration in examining the factors affecting PASU in those schools.

\section{Design and Sample}

The present study is based on a qualitative, exploratory design using purposive sampling. It was conducted among adolescents in public, coeducational schools, focusing on prefects (i.e., student-leaders) as participants. In an ordinary secondary school in Uganda, prefects form an interface and mediate between students and school administrators. Prefects were therefore deemed instrumental in supplying reliable information and opinions regarding student affairs in their respective schools. We conducted rigorous focus group discussions (FGDs) until saturation was reached at the $12^{\text {th }}$ FGD. Data collection at this point was terminated, in preparation for final analysis.

\section{Instrument}

A focus group guide was used to generate data from student-leaders based on the main question: "What factors influence use of psychoactive substances among students in your school?" All the FGDs were therefore based on the study theme "factors influencing substance use among adolescents in schools." The discussions followed a twoway interaction between the moderator and study participants, and between participants themselves. During the FGDs, the moderator initiated, regulated, and sustained (through probes) the conversations, based on the study theme and sub-themes. The study participants, with the guidance of the moderator, extensively and thematically discussed the question of the study.

\section{Ethical Consideration}

Approval for data collection was initially sought from the Institutional Review Board of Mbarara University of Science and Technology in Mbarara, Uganda. Further clearance was sought and obtained from the Uganda National Council of Science and Technology and from the Office of the President of the Republic of Uganda. The final permission to interact with students was obtained from respective heads of schools. Before the discussions began, the participants' written and informed consent was first obtained. Explanations regarding study aims, the right to decline participating, the right to withdraw, and issues of confidentiality were articulated to the students prior to the start of each FGD.

\section{Analysis}

Data analysis was ongoing during and after data collection using thematic content analysis, a phase-by-phase manual analysis of thematic data categories. Thematic content analysis was preferable because it enabled scrutiny of conceptual similarities and discovery of patterns of themes, which identified what study participants talked about most frequently and collected related themes. In the first phase, recordings of FGDs were played and listened to at least twice before they were summarized, a benchmark for preliminary coding of emerging trends. During the second phase, primary transcription of the interviews was completed and substantively evaluated for accuracy and coherency. A more categorical analysis was then started, first in broader terms and then zeroing in on specific categories. Final codes reflecting trends in study topic were then refined.

\section{Results}

The study engaged 70 prefects in 12 FGDs. The mean age of study participants was $18.51(S D=1.49)$. Majority of the study participants were males $(72.9 \%)$ and from the grade level senior five (51.4\%). The Ugandan system has a 7:4:2 system of schooling. That is, students spend seven years at the primary level, four years at the secondary level (senior one to senior four), and two years at the advanced level (senior five and senior six). Students then join university or other institutions of higher learning after senior six. Students from lower secondary (senior one and senior two) did not feature among the sample, as all schools are mandated by the Ministry of Education guidelines to select prefects only from upper secondary section. All prefects had spent a year or less in their respective positions as student-leaders. This was expected, as a student-leader's term of office in all Ugandan schools is mandated to last one year. 
All FGDs (100\%) gave the idea that peers play a big role in influencing adolescents in schools to use psychoactive substances. A participant from group six elaborated on influence of peers on PASU in school:

The other point of mine comes: mainly it is peer influence - like if you stay in a place say in a hostel where there is drug addiction, you also feel like being part of the group. Yeah, okay after being used to ... . [hesitation] okay after being introduced to the group of drug use, you end up being part of the group. Yeah - part of the peer influence that uses the drugs. (NAI04, July 4, 2013)

Additionally, relief and managing stressful situations (especially domestic stressors) was mentioned in the FGDs as one of the factors that contribute to PASU among students. Participants emphatically reasoned that PASU was a means of solving or repressing the day-to-day pressures of life. A participant emphasized the issue of using substances for stress management:

Are factors also reasons? [Moderator says 'yes.'] Actually me personally I also take drugs! Yeah, more especially alcohols - these things like Bell and Guinness. There is a belief and this belief is on my side as well as that of other students: This belief is that such drugs can relieve stress. When you take a bit you feel relief and you are compelled to rest. It is because they intoxicate your brain and they weaken your cells. Yeah, that's why you rest. (NAB01, July 4, 2013)

Another participant stated:

Now, for the alcohol that I named as knock-out, students use it as a problem knocker - so that it helps them to avoid those problems and to forget them. Problems like over-stress (too much stress) at home especially by guardians one thinks that is the only solution to the problem. Some of them also take alcohol as a means of warm up so that 'you are sharp-sharp' or bright in class! Yeah, especially during examination times. (ESI03, July 8, 2013)

The students also argue that certain academic subjects at their respective schools are disliked or hated, as they are regarded as difficult, hard, and boring. This implies that some students face challenges concentrating in those subjects. The quote below from a participant shows that students perceive PASU as having an amplifying influence and offer a means through which they gain confidence to concentrate on such hated subjects:

Some other factor - some of us today [hesitation] some of us there are some subjects we hate [laughter from the other group members] [hesitation]. Yeah, as a result of that students may decide to go out and take alcohol so that they can be steady in class [laughter, moderator asks the participant what she meant by 'steadiness'] . . . Mm [hesitation]. Yeah, if you are not drank you can't be active in that subject. (WFS06, June 24, 2013)

It was also reported that students held their parents and society accountable for substance use among adolescents in schools. Blame of parents for substance use among students was twofold. First, participants thought some parents themselves use psychoactive substances and therefore serve as examples to their children. Second, they thought it was permissiveness of parents and society that pushed students to PASU, as some of the participants from group six and group 11 respectively elaborated:

...family-like permissiveness of parents. (EMI04, July 11, 2013).

Relatives for example like he said, if you have brothers who take such drugs you also end up taking them - even parents! Those who smoke, they also like ... in some other families where taking alcohol is normal you find students from those families emulating their parents. (CEE03, July 18, 2013)

To some extent, it was observed that students are involved in PASU to gain confidence for co-curricular activities, especially during entertainment. As one study participant elaborates:

"Marijuana for example - when someone wants to entertain others they may not be having selfconfidence, they then take marijuana to become more active.” (WME05, June 13, 2013).

Related to entertainment was learning from role models, or what they termed "the bandwagon effect." For example, one student confessed to having tasted cocaine. When asked for the reasoning for using it, the student asserted that "Bobi [musician] influenced me." And students from group four had a similar argument:

"Some students believe that if you take something dry like marijuana you become a musician. So they take it when they are practicing for encouragement - you develop a talent of music just like celebs.” (NGH05, July 1, 2013).

Participants surprisingly mentioned "coupling” as one of the factors that influence PASU in schools. While it may be common for students in coeducational schools to "couple," it was not expected to be a factor for PASU in those schools. When asked to explain how engaging in intimate relationships led to substance use, a participant from group two said,

"Home problems or maybe the girl friend has dropped him or vice versa." (WKB01, June 18, 2013).

Uncommonly, other participants linked PASU to watching pornography. The student below emphasized the argument:

Pornography - like the students when they watch those things [pornographic materials], they tend to practice what they see like taking alcohol like 
those dancers. Sometimes they may be drinking and this can force those watching them to practice because they want to be like those stars. (WKD04, June 18, 2013)

From the students' FGDs, it could be inferred that when threatened by challenges, students turn to peer groups, culminating into self-fulfilling behaviors, including PASU.

\section{Discussion}

As in other comparable studies (e.g., Bergen, Martin, Roeger, \& Allison, 2005; Dolcini et al., 2013; Oakley, 1974; Pengpid \& Peltzer, 2013), this study reveals that PASU among school-going adolescents is influenced by a number of individual and exterior factors. Peer influence was pinpointed by all FGDs as a major stimulus to adolescent substance use. A possible explanation for this finding could be that while adolescents learn good behaviors from their peers, it is probable that they equally adopt maladaptive and delinquent conducts, including PASU, from the same peers (Van Ryzin \& Dishion, 2014). The result that peer influence is a major factor in PASU confirms previous related studies (e.g., Donovan, 2004; Yusoff et al., 2014) and is more so manifested by the social learning theory of PASU (Donovan, 2004).

In a social learning context, peers via observation, imitation, and positive reinforcement serve as a locus of learning of substance use (Giovazolias \& Themeli, 2014; Petraitis et al., 1995). Positive reinforcement probably occurs as substance use receives undeserving glorification as a cool, stylish, and trendy activity among youth. It has been suggested, for example, that peers encourage smoking initiation (Walsh \& Tzelepis, 2007) and subsequent smoking behavior (Dawson, Sotelo, Roesch, \& Klonoff, 2013), despite the health and social flaws associated with use of tobacco and its products (Jiloha, 2009). The phenomenon of peer influence and social learning is possibly reflected in media commercials portraying teenagers actively promoting alcoholic and tobacco products. Indeed, specific corporate companies in Uganda commonly do aggressive advertising featuring youthful models absorbed in PASU euphoria. In fact, some of the enterprises go an extra mile in erecting billboards along highways and in major towns with successful and talented youth, like musicians, modeling PASU. It is not surprising therefore for adolescents in urban-based schools to attribute substance use to peer models in their vicinities.

Other related studies among adolescents in the United States, United Kingdom, Canada, and elsewhere generally implicate substance use as providing a common activity through which teenagers bond with peers as well as "break the ice" in new social situations (Weinberg, Rahdert, Colliver, \& Meyer, 1998). Peers, for example, were reported to influence adolescents' drinking behaviors over and above individual characteristics (Sanhueza et al., 2013). Related studies (e.g., Fleary et al., 2013) also established that PASU among adolescents is related to peer-influence. In a similar context, Onya, Tessera, Myers, and Flisher (2012) underscore the role of peers as an influence to adolescent PASU. The vast sources cement our understanding that peer influence is a universally recognized factor associated with PASU.

Despite the revelations regarding peer influence and PASU, there is a marked contextual difference in the current findings and sources elsewhere. Contrary to this study, Walsh and Tzelepis (2007) found that peer pressure to use substances was mentioned by a small number of students from low socio-economic status families. Walsh and Tzelepis, however, made their observations from a study done in the United Kingdom, where societal stratification is based, among other things, on social polymorphism. The difference between the studies could hence originate from some striking disharmony in Ugandan and UK racial and socio-economic undercurrents.

Participants in this study pointed to their relatives (e.g., parents and siblings) and school neighboring communities as other crucial factors contributing to PASU in schools. Whereas a number of studies (e.g., Brook et al., 2006) pinpoint parental influence as a foremost factor towards PASU, such was not among major arguments for participants of the present study. However, research on neighborhood influences suggests that some ecological factors exert significant influences on adolescent substance use, and that social contact among neighbors may be one of the primary mechanisms through which transmission of substance use among students operates (Barnes et al., 2013). Furthermore, exposure opportunities such as high alcohol outlet density or availability of psychoactive substances have been cited as contributing factors to PASU among adolescents (Sanhueza et al., 2013).

The observation that PASU is related to adolescents' interactions among themselves and other people mirrors the diffusion theory of substance use. As Ferrence (2001) posited, the diffusion theory is concerned with the "contagious" nature of PASU. It is honestly inferred and acknowledged that social integration affords favorable avenues for exchange of psychoactive substances among students and communities. The aforementioned literature moreover depicts school environments as not being secluded, and hence we comfortably argue that PASU networks certainly spread among them.

The present study also reports noteworthy results regarding students' use of psychoactive substances to boost confidence during entertainment. This finding is not in isolation, as Bekman et al. (2011) assert that adolescents consume alcohol to enhance "social facilitation." Social facilitation in this context denotes increased ability to perform socially determined tasks, including entertainment (Tulu \& Keskis, 2015). Further confirmation of the present study's findings is reflected by Surujlal and Keyser (2014) in their study exploring students' demographic variables and alcohol consumption, where they attribute substance use to the desire to perform in athletics and related forms of co-curricular activities. 
It is worth mentioning that, while the factors surrounding PASU among adolescents in schools have been found to be distinct, including PASU expectancies (Bekman et al., 2011) and social contingencies (Botvin \& Griffin, 2007), schooling atmosphere stands at the epitome of PASU among adolescents (Reddy et al., 2007; Yusoff et al., 2014). Students in the respective schools where data collection for this study was done live a college-like life, yet they are too young to make mature, meaningful decisions as college students would do. For instance, in a typical public day-school located in a slum-like area, a number of day-scholars, especially boys, live in rented rooms outside schools, though within nearby communities. This arrangement was to facilitate commuting to and from school. Students are inevitably influenced by such environments, and their PASU behavior perhaps reflects a bigger picture of the society where they live.

Students clearly spotted social influences and domesticrelated aspects as being the principal factors for PASU, not forgetting "reasoned actions" for them to perform better in school. As earlier rationalized, emphasis on social facets mirrors social learning and diffusion theories at work, with peer influence at the heart of students' responses to the study question. This is understandable, as students are at a stage where peers and peer groups provide forums for selfexpression. Desire for self-expression ostensibly culminates into self-fulfilling behaviors, including PASU. Present study findings are consequently interpreted in consideration of the philosophies underlying overall conceptualization of the study.

It is essential to enunciate that the present study has limitations. PASU essentially represents global and cosmopolitan issues whose factors touch a large spectrum of populations. Limiting the subject of PASU to public schools, and moreover to prefects, could have undermined our ability to generalize the phenomenon elsewhere. Moreover, the study findings may not very well relate to boarding schools that limit students within the confines of the school premises for longer periods. Comparatively, the category of schools considered by this study may be unique to particular countries like Uganda and uncommon in other parts of the globe. Such a shortfall may have resulted in our findings being conceptually localized and only replicable in a Ugandan context.

\section{Implications}

The present study findings probably inform policy design and implementation for young people in Ugandan schools. Firstly, peer influence has been implicated as being at the peak of the prime factors affecting PASU in schools. Based on such a revelation, schools ought to regulate peer networks that serve as prototypes for substance use. Secondly, educators ought to exploit the present study findings to construct a comprehensive school curriculum that seeks to mitigate the factors associated with PASU in schools. There could be, for example, modified curricula to include life skills related to peer resistance and social intelligence as integral mechanisms to reduce substance use among students.

\section{Further Research}

The present study qualitatively investigates the factors influencing PASU in schools, focusing on prefects as the unit of analysis. Whereas this technique enabled exploration of the study subject in depth, the findings may not be generalizable to a wider perspective. Similar but quantitative approaches are advocated for, as they can tap into the subject in a more generalizable point of view. Peer and familial factors in particular deserve due consideration as they emerged most frequently during FGDs and were reflected by various previous studies (e.g., Geramian et al., 2012).

\section{Conclusion}

The present study results intricately suggest that the factors influencing PASU among adolescents in schools resonate among individual adolescents, circumstances surrounding them, and the environment in which adolescents find themselves. The findings further reflect contemporary adolescent values (e.g., Colby et al., 2013) coupled with an increasingly receptive and permissive society that fuels PASU among students.

\section{References}

Agius, P., Taft, A., Hemphill, S., Toumbourou, J., \& McMorris, B. (2013). Excessive alcohol use and its association with risky sexual behavior: A crosssectional analysis of data from Victorian secondary school students. Australian and New Zealand Journal of Public Health, 37(1), 76-82. doi:10.1111/17536405.12014

American Academy of Pediatrics. (2010). Policy statement-Children, adolescents, substance abuse, and the media. Pediatrics, 126, 791-799. doi:10.1542/peds.2010-1635

Barnes, G. M., Welte, J.W., Tidwell, O. M., \& Hoffman, J. H. (2013). Effects of neighborhood disadvantage on problem gambling and alcohol abuse. Journal of Behavioral Addictions, 2(2), 82-89. doi:10.1556/JBA.2.2013.004

Bekman, N. M., Anderson, G. K., Trim, R. S., Metrik, J., Diulio, A. R., Myers, G. M., \& Brown, S. A. (2011). Thinking and drinking: Alcohol-related cognitions across stages of adolescent alcohol involvement. Psychology of Addictive Behaviors, 25, 415-425. doi:10.1037/a0023302

Bergen, H. A., Martin, G., Roeger, L., \& Allison, S. (2005). Perceived academic performance and alcohol, tobacco, and marijuana use: Longitudinal relationships in young community adolescents. Addictive Behaviors, 30(8), 1563-1573.

Botvin, J. G., \& Griffin, K. W. (2007). School-based programmes to prevent alcohol, tobacco and other drug use. International Review of Psychiatry, 19, 607615. doi:10.1080/09540260701797753

Brook, S. B., Pahl, T., Morojere., N. K., \& Brook, D. W. (2006). Predictors of drug use among South African Adolescents. Journal of Adolescent Health, 38(1), 2634. 
Caprara, G. V., Regalia, C., \& Bandura, A. (2002). Longitudinal impact of perceived self-regulatory efficacy on violent conduct. European Psychologist, 7, 63-69.

Colby, M., Hecht, M. L., Miller-Day, M., Krieger, J. L., Syvertsen, A. M., Graham, J. W., \& Pettiggrew, J. (2013). Adapting school-based substance use prevention curriculum through cultural grounding: A review and exemplar of adaptation processes for rural schools. American Journal of Community Psychology, 51(1), 190-205. doi:10.1007/s10464012-9524-8

Conway, P. K., Vullo, C. G., Nichter, B., Wang, J., Compton, W. M., Iannotti, R. J., \& Simons-Morton, B. (2013). Prevalence and patterns of polysubstance use in a nationally representative sample of $10^{\text {th }}$ graders in the United States. Journal of Adolescent Health, 52, 716-723. doi:10.1016/j.jadohealth.2012. 12.006

Cronk, C. E., \& Sarvela, P. D. (1997). Alcohol, tobacco, and other drug use among rural/small town and urban youth: A secondary analysis of the monitoring the future data set. American Journal of Public Health, 87, 760-764.

Dawson, D. B., Sotelo, F. L., Roesch, S. C., \& Klonoff, E. A. (2014). Testing the invariance of adolescent survey-based smoking-related behaviors across ethnic groups and gender. Journal of Health Psychology, 19(12), 1576-1585. doi:10.1177/1359105313495907

Dokua, D., Koivusiltac, L., Raisamob, S., \& Rimpeläb, A. (2012). Tobacco use and exposure to tobacco promoting and restraining factors among adolescents in a developing country. Public Health, 126, 668-674. doi:10.1016/j.puhe.2012.05.003

Dolcini, M. M., Catania, J. A., Harper, G. W., Watson, S. E., Ellen, J. M., \& Towner, S. L. (2013). Norms governing urban African American adolescents' sexual and substance-using behavior. Journal of Adolescence,36(1), 31-43. doi:10.1016/j.adolescence. 2012.09.002

Donovan, J. E. (2004). Adolescent alcohol initiation: A review of psychosocial risk factors. Journal of Adolescent Health, 35, 7-18. doi:10.1016/j. jadohealth.2004.02.003

Ferrence, R. (2001). Diffusion theory and drug use. Addiction, 96, 165-173. doi:10.1080/ 09652140020017030

Fleary, A. S., Heffer, R. W., \& McKyer, E. J. L. (2013). Understanding non-prescription and prescription drug misuse in late adolescence/young adulthood. Journal of Addiction, 709207. doi:10.1155/2013/709207

Geramian, N., Akhavan, S., Gharaat, L., Tehrani, A. M., \& Farajzadegan, Z. (2012). Determination of drug abuse in high school students and their related knowledge and attitude. Journal of Pakistan Medical Association, 62(3), 62-66.

Giovazolias, T., \& Themeli, O. (2014). Social learning conceptualization for substance abuse: Implications for therapeutic interventions. The European Journal of Counselling Psychology, 3(1), 69-88. doi:10.5964/ ejcop.v3i1.23
Hockenbury, D. H., \& Hockenbury, S. E. (2006). Psychology. New York, NY, United States: Words Worth.

Jiloha, R. C. (2009). Social and cultural aspects of drug abuse in adolescents. Delhi Psychiatry Journal, 12, 167-175.

Kacwamu, R. (2010, November 15-18). Alcohol abuse among secondary schools: mentor pops in Kampala schools. In the proceedings of the first Kettil Bruun Society thematic meeting in Africa on alcohol epidemiology and policy, Kampala, Uganda.

Kalichman, S. C., Simbayi, L. C., Kaufman, M., Cain, D., \& Jooste, S. (2007). Alcohol use and sexual risks for HIV/AIDS in Sub-Saharan Africa: Systematic review of empirical findings. Prevention Science, 8, 141-151. doi:10.1007/s11121-006-0061-2

Kandel, D. B., \& Andrews, K. (1987). Processes of adolescent socialization by parents and peers. International Journal of Addiction, 22(4), 319-342.

Karen, K. K. (1993). Understanding human behaviours and the social environment. Chicago, IL, United States: Nelson-Hall.

Karriker-Jaffe, K. J., Zemore, S. E., Mulia, N., JonesWebb, R., Bond, J., \& Greenfield, T. K. (2012). Journal of Studies in Alcohol and Drugs, 78, 865-873.

Laflin, M., Edmundson, E. W., \& Moore-Hirschl, S. (1995). Enhancing adoption of an alcohol abuse prevention program: An application of diffusion theory. Journal of Primary Prevention, 16(1), 75-83.

Marks, D. F., Murray, M., Evans, B., Willig, C., Woodwall, C., \& Syke, C. M. (2005). Health psychology: Theory, research and practice (2nd ed.). London, England: SAGE.

McLeod, S. A. (2016). Bandura - Social learning theory. Retrieved from www.simplypsychology.org/bandura. html

Milam, J. A., Furr-Holden, C. D. M., Harrell, P. T., Whitaker, D. E., \& Leaf, P. J. (2012). Neighborhood disorder and juvenile drug arrests: A preliminary investigation using the NIfETy instrument. The American Journal of Drug and Alcohol Abuse, 38(6), 598-602. doi:10.3109/00952990.2012.701357

Moore, M. J., \& Werch, C. E. (2005). Sport and physical activity participation and substance use among adolescents. Journal of Adolescent Health, 36, 486493.

Mpabulungi, L. (2003). Report on the results of the global youth tobacco survey in Uganda, Kampala: A GYTS report. Kampala, Uganda: Parliament Research Service.

Muggaga, R. (2010, April 11). Cocaine, heroin now rampant in schools. Retrieved from http://www.observer.ug/ index.php

Oakley, S. R. (1974). Drugs, society and human behaviour. New York, NY, United States: Mosby, CV.

Oman, R. F., Tolma, E. L., Vesely, S. K., \& Aspy, C. B. (2013). Youth gender differences in alcohol use: A prospective study of multiple youth assets and the neighborhood environment. Open Journal of Preventive Medicine, 3(2), 219-227. doi:10.4236/ ojpm.2013.32030 
Onya, H. E., Tessera, A., \& Myers, B. (2012). Community influences on adolescents' use of home-brewed alcohol in rural South-Africa. BMC Public Health, 12, 42. doi:10.1186/1471-2458-12-642

Onya, H. E., Tessera, A., Myers, B., \& Flisher, A. (2012). Adolescent alcohol use in rural South African high schools. African Journal of Psychiatry, 15(5), 352357. doi:10.4314/ajpsy.v15i5.44

Pengpid, S., \& Peltzer, K. (2013). Prevalence and psychosocial correlates of illicit drug use among school-going adolescents in Thailand. Journal of Social Sciences, 34(3), 269-275.

Perkins, H. W. (1997). College student misperceptions of alcohol and other drug norms among peers: Exploring causes, consequences, and implications for prevention programs. In Designing alcohol and other drug prevention programs in higher education: Bringing theory into practice (pp. 177-206). Washington, D.C., United States: The Higher Education Center for Alcohol and Other Drug Prevention, U.S. Department of Education.

Petraitis, J., Flay, B. R., \& Miller, T. Q. (1995). Reviewing theories of adolescent substance use: Organizing pieces in the puzzle. Psychological Bulletin, 117(1), 67-86.

Reddy, P., Resnicow, K., Omardien, R., \& Kambaran, N. (2007). Prevalence and correlates of substance use among high school students in South Africa and the United States. American Journal of Public Health, 97, 1859-1864.

Rukundo, A. (2012). Peer pressure, academic and social experience of secondary school teenagers in the outskirts of Mbarara Municipality, Uganda. Journal of Educational Sciences and Psychology, 2(1), 82-86.

Sanhueza, G. E., Delva, J., Bares, C. B., \& Grogan-Kaylor, A. (2013). Alcohol consumption among Chilean adolescents: Examining individual, peer, parenting and environmental factors. International Journal of Alcohol and Drug Research, 2(1), 89-97. doi:10.7895/ ijadr.v2il.7l

Seay, K. D., \& Kohl, L. P. (2013). Caregiver substance abuse and children's exposure to violence in a nationally representative child welfare sample. Journal of Social Work Practices in the Addictions, 13(1), 70-90. doi:10.1080/1533256x.2013.756335

Surujlal, J., \& Keyser, E. (2014). Exploring differences in demographic variables and alcohol consumption amongst university student-athletes. Mediterranean Journal of Social Sciences, 5, 820-826. doi:10.5901/mjss.2014.v5n23p820

Sznitman, S. R., \& Romer, D. (2014). Student drug testing and positive school climates: Testing the relation between two school characteristics and drug use behavior in a longitudinal study. Journal of Studies on Alcohol and Drugs, 75, 65-73.

Telzer, E. H., Gonzales, N., \& Fuligni, A. (2013). Family obligation values and family assistance behaviors: Protective and risk factors for Mexican-American adolescents' substance use. Journal of Youth and Adolescence, 43(2), 270-283. doi:10.1007/s10964013-9941-5
Thompson, L., Rivara, P. K., \& Whitehill, J. M. (2015). Prevalence of marijuana-related traffic on twitter, 2012-2013. Cyber Psychology, Behavior, and Social Networking, 18(6), 311-319. doi:10.1089/cyber.2014. 0620

Tulu, S. K., \& Keskis, W. (2015). Assessment of causes, prevalence, and consequences of alcohol and drug abuse among Mekelle University CSSL $2^{\text {nd }}$ year students. American Journal of Applied Psychology, (3)3, 47-56. doi:10.12691/ajap-3-3-1

Van Ryzin, M. J., \& Dishion, J. T. (2014). Adolescent deviant peer clustering as an amplifying mechanism underlying the progression from early substance use to late adolescent dependence. Journal of Child Psychology and Psychiatry, 55(10), 1153-1161. doi:10.1111/jcpp.12211

Wallace, J. M., \& Muroff, J. R. (2002). Preventing substance abuse among African American children and youth: Race differences in risk factor exposure and vulnerability. The Journal of Primary Prevention, 22, 235-261.

Walsh, A. R., \& Tzelepis, F. (2007). Adolescents and tobacco use: Systematic review of qualitative research methodologies and partial synthesis of findings. Substance Use and Misuse, 42, 1269-1321. doi:10.1080/10826080701204904

Warren, J. C., Smalley, K. B., \& Barefoot, K. N. (2015). Perceived ease of access to alcohol, tobacco and other substances in rural and urban US students. The International Electronic Journal of Rural and Remote Health Research, Education, Practice and Policy, 15(4), 3397.

Weinberg, M. D., Rahdert, E., Colliver, J. D., \& Meyer, D. G. (1998). Adolescent substance use: A review of the past 10 years. Journal of American Academy of Child and Adolescent Psychiatry, 37, 253-261.

Wood, D. (2009). Patterns of substance abuse among school-age children: Clinical paper, Mental Health Matters. Retrieved from http://mental-healthmatters.com/patterns-of-substance-abuse-amongschool-age-children-clinical-paper/

Yusoff, F., Sahril, N., Rasidi, N. M., Zaki, N. A. M., Muhamad, N., \&Ani, N. (2014). Illicit drug use among school-going adolescents in Malaysia. Asia-Pacific Journal of Public Health, 26(55), 100S-107S. doi:10.1177/1010539514542425 